UDC 373.3

Gayane YEGANYAN

Gayane HARUTYUNYAN

\title{
DIAGNOSTICS AS A PRECONDITION OF VALUE ORIENTATION IN PRIMARY SCHOOL
}

\section{Abstract}

The demands put forward the contemporary primary school are being changed year by year due to a number of factors - political, socio-economic, cultural, etc. Nowadays, when there are confusion and a struggle for values around the world, every nation must strive to recognize and preserve its ethnic moral values in harmony with contemporary demands. The purpose of contemporary education is not limited by equipping the individual with knowledge and skills, but also to develop the certain moral qualities, and one of the most important functions of a teacher is to shape the worldview of students. The pedagogical diagnostics with its rich toolkit, a wide selection of methods and methodology, is a prerequisite for value orientation in the elementary school and contributes to the formation of the primary schooler value system of significant values important for the individual and society.

Keywords: elementary school, primary schooler, value orientation, diagnostic thinking, diagnostics, methodology, factual data, value, quality.

In the context of a changing world economy, all aspects of life and its perception, including education, have been changed.

One of the most important requirements of transformative education policy is the establishment of an elementary school as the basis of contemporary pedagogy in a unified educational field, which will only be provided with its stable 'subject'.

Elementary school is the primary educational level of the contemporary system of general education.

Elementary school education is considered to be one of the primary and important periods in the education system. The purpose of education is not limited by equipping the individual with knowledge, but also to develop certain moral qualities which are the indissoluble component of education.

Primary school age (from 6 to $9-10$ years old) is the period of personal development when transitioning from careless childhood to a responsible period with clear requirements.

Admission to school in every child's life is considered a breakthrough period. The beginning of school education dramatically changes his lifestyle. The carelessness of the 
preschoolers, their activities, the games are replaced by the fulfilment of many demands and duties, with a daily life full of restrictions. From now on, the child is obliged to attend school daily, to study consistently and strenuously, to maintain a daily schedule, to comply with the requirements and norms of school life, to engage in the work of the school curriculum, to perform teacher assignments and homework diligently and to strive endlessly for high performance and for being exemplary "Individual" in teaching.

Entrance to a new social environment, the beginning of a child's educational activities require a new level of qualitative development, organization of mental processes (perception, attention, thinking, memory) and a higher level of self-management.

A contemporary elementary school teacher should do his / her educating, developing and nurturing work on the base of constantly changing and evolving personalities of students.

The demands put forward the contemporary primary school are being changed year by year due to a number of factors - political, socio-economic, cultural, etc.

Constantly changing situations are purposefully directed to create a sustainable system of fact-based end results, where the availability of professional-diagnostical, personalsearchable and predictive-creative competencies of a teacher are important, with set professional requirements to be inventive, advanced skilled, and quickly responsive to the changes. On the way to solving such problems, especially elementary school teachers should be the bearer of diagnostic thinking along with a firm commitment to human and national values.

The pedagogical diagnostics along with rich toolkit and a wide range of methods, as well as the application of methodologies, enables to clearly identify the cause of a particular problem, enables to find out the level of education and socialization of the student, as well as his readiness for the school and study, taking into consideration his physiological, communicative-psychological, comprehensive and other diagnostic features. "An important principle of diagnostics is the complex study of all phenomena in their interdependence" [1, p. 162].

The main task of a primary school teacher is to obtain clear information not only about each student's educational opportunities and readiness, but also about value prerequisites by designing the development, prevention, and remedial guarantees to the desired endpoints of the current state.

In the contemporary education system, children attend school not from age 7 but from age 6 . In elementary school, revealing a child's personality, abilities, inclinations and creative potential is a continuous process and main focus of a teacher's daily work - value guidance. By the way, it is important and necessary since school admission. Therefore, a contemporary 
elementary school teacher must master and perform diagnostic and methodological tasks, perform self-diagnostics, objectively ascertain his / her professional and personal qualities in order to improve his / her own abilities, to successfully solve the problems arising in the education process.

In terms of contemporary globalization, when there are confusion and struggle of European, Asian, American values throughout the world, every nation should strive to recognize and maintain its ethnic moral values by combining those with modern demands.

There are national values that do not need timing and human order: the preservation and transmission of traditions, the preservation of language, religion and culture, etc. In the Armenian environment, there is a number of factors that are worthy of protection: the family with traditional upbringing, the school accompanied by the competent help of a teacher, the society with its habits, etc. "The purpose of contemporary upbringing should be aimed at setting conditions for the child development based on interests, needs, inclinations, free creative basis and building of education upon them" [2, p. 5].

Here the role of the teacher is important both in the child's life and in education. The teacher is authorized by the society and the pedagogical community to perform educational activities in his exemplary work style, with behavioural characteristics ranging from internal moral responsibility to the maintenance of pedagogical tact, the existence of psychological equilibrium, and responsibility in the pedagogical staff.

Every teacher who works with primary schoolers, while knowing his best and taking into account the students' adaptation characteristics to a new school environment, their dynamically changing personal qualities, values and influence of environmental factors, will make these a basis for his work and activity to increase interest for studying and thus to make education and idea of being intelligent as of right values perception for primary schoolers. One of the most important functions of a teacher is to cultivate enduring values, faith, and love.

Taking into account the professional activities of the specialist, Isayev offers the following classification of teacher's professional values:

1. Values-goals that reveal the meaning and significance of the teacher's professionalpedagogical goals.

2. Values-means that reveal the importance of ways and methods of professionalpedagogical activities.

3. Values-relationships that reveal relationships as a key mechanism of a holistic educating process.

4. Values-knowledge that reveal the meaning and significance of psychological and 
pedagogical knowledge in the implementation process of educating.

5. Values-attributes that reveal the personality of the teacher, the diversity of the teacher's personal, communicative, and professional qualities as a mandatory condition of professional-pedagogical activity, teacher's ability to create, the ability to design professional activities, and the ability to predict the consequences, etc. [3, p. 94].

The value is a unique understanding of the world and the phenomena that take place in it - formed not only on the basis of acquired knowledge and information but also on the basis of one's own life experience. It is a norm of social behaviour that can serve for the satisfaction of a person's needs.

At primary school age, a worldview of a child is formed that integrates human values, morals and aesthetics and is a decisive factor for the development of the individual. The evaluation has a unique place in the worldview as it reveals and evaluates the significance of the world and things. A worldview is a way of perceiving, understanding and evaluating the environment around which people formulate their own attitudes towards the world. So, in the worldview, there are generalizations of knowledge and ideas, ideals and norms that are most important and significant for human life and activity. Faith and conviction as a stable mental and emotional state of a person are an important structural component of the worldview. Due to their enduring beliefs, people gain a great deal of confidence in their own ideas, views, and principles, and get a confident determination to achieve their goals.

The development of ethical motives of a primary schooler is the top priority, where the formation of ideals plays an important role - with a clear message (mainly via different books or TV characters) and influence on their externalities. The teacher is the only authority and the ideal for a primary schooler. "A well-organized access to a pedagogical information environment by the teacher will facilitate the re-evaluation of pedagogical values (which he has implemented) towards education and will complement his research position on the educational process" [4, p. 151].

Referring to the concept of value, we should note, that the norms formed in society are the highest manifestations of value systems (i.e., the dominant views on what to consider good, right, or desirable). The concepts of value and norm are different. Values are abstract, general concepts, and norms are rules or guiding principles of human behaviour in certain situations. Value systems formed in society play an important role in influencing the norms. Values can include health, love, family, children, close friends, self-employment, enjoyment of work, wealth, spiritual values, spiritual growth, religion, leisure, hobbies, creative selfexpression, self-education, social status, freedom (of speech, choice, etc.), stability, etc.

We conducted research to find out the values of primary schoolers in order to reveal the 
personal and social qualities and values of schoolchildren. For teachers, the results of this survey will serve as a basis for factual thinking, giving the opportunity to outline an active, proactive citizen of Armenia with national values.

The research was conducted in Nerses Ashtaraketsi School \# 1 in Ashtarak, with 16 teachers and 74 students. We selected Schwartz's "Value Orientation" methodology (1992) [5] as a diagnostic methodology of our study. Schwartz's theory of value orientations considers the cultural values on the one hand as ideals for a person, and on the other hand, as normative behavioural orientations that a person must follow. According to the methodology, all values are differentiated by the possibility of two list options: social and individual. The selection of values in List 1 and List 2 was assessed on the basis of the following criteria and presented to students as "important", "less important", "not important"; to rate on a scale with a high score (7), and claims that contradict their values with a low score $(-1)$, respectively.

The first social list of values contains qualities important to society (equality, respect, freedom, discipline, etc.). The results of the research are presented below [see Chart 1]:

Chart 1

Social Values ( $1^{\text {st }}$ list of values)

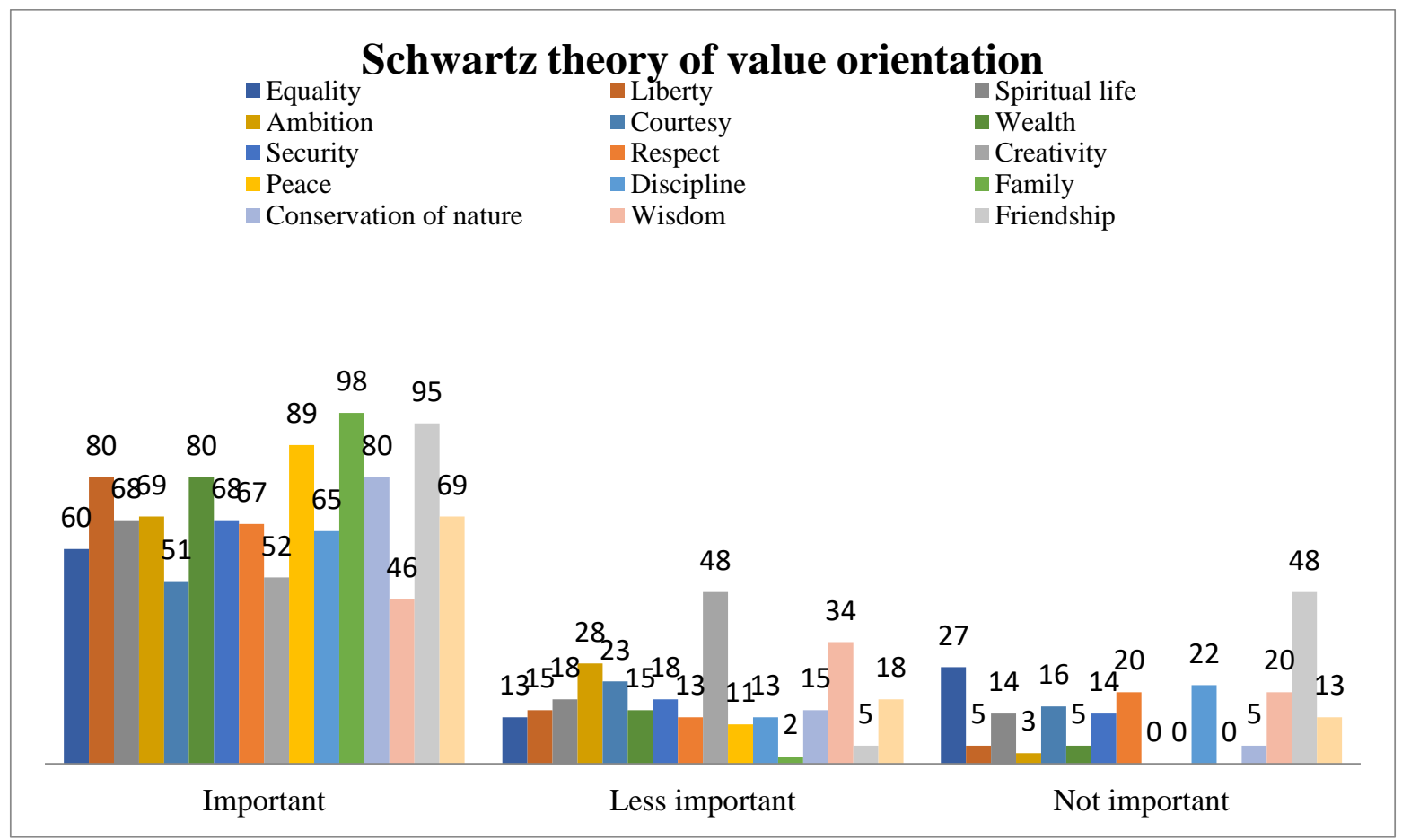

Sharing Schwarz's "Value Orientation" methodology with primary schoolers, we found out, that family (98\%), friendliness (95\% component of moral upbringing) are their primary values. Fortunately for us, primary schoolers stated Liberty as a value norm (80\%), which is one of the components of legal education. Nature conservation (80\%) is also considered important, which is necessary for preserving contemporary eco-environment. 
The second, personalized list of values of the methodology contains qualities that are important for the student the bearer of which is himself (honest, modest, self-contained, discreet, etc.). The results of the research are presented below [see Chart 2].

Chart 2

Individual Values ( $2^{\text {nd }}$ list of values)

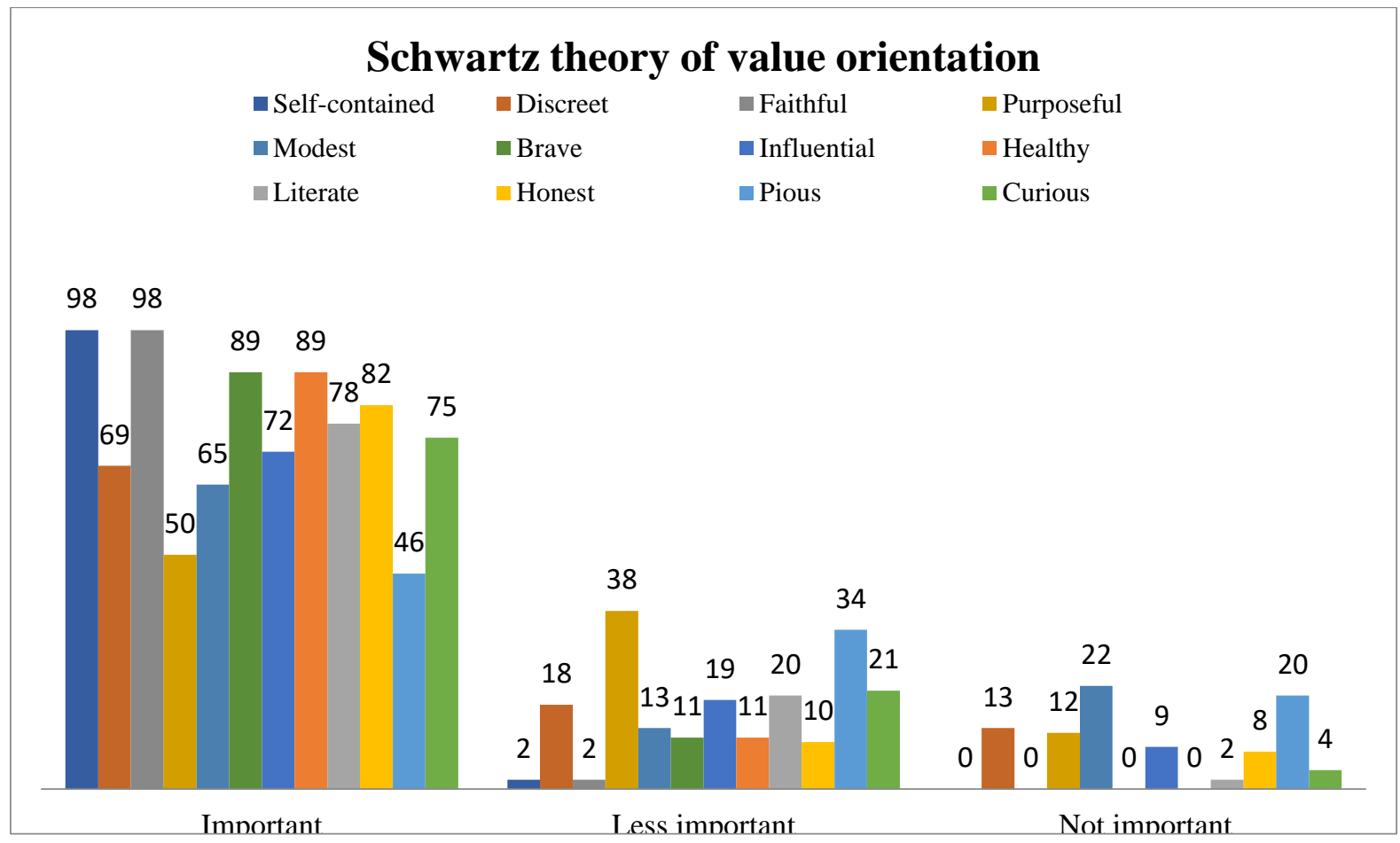

The results of the study show that in the current educational environment, one's selfreliance $(98 \%)$, as well as honesty (82\%) and faith (98\%) in the friendship and in general communication are important.

Summarizing the results of applied Schwartz's "Value Orientation" methodology and analyzing the data obtained, we can state, that present-day elementary schoolchildren have emphasized the following values: friendliness, honesty, faith, environmental protection, respect, freedom and self-reliance. The personal and social values of primary schoolers are the re-conceptualization of values theoretically embedded in society that can be a precondition for the formation of sustainable values only with competent diagnostic help of a teacher.

The formula to "see, recognize, evaluate, convince, display, convey" must serve as a basis for the orientation and formation of each value.

Therefore, we believe that everyone involved in the education process should consider the following key points in their daily work:

1. The fixation of values historically shaped and passed from generation-togeneration everywhere and mainly in the general education field;

2. The correct perception of values; 
3. Guaranteed realization of values that are guaranteed for clear vision and forecast.

It is important for teachers to take into account the peculiarities of the primary schoolers and to create an ever-changing, dynamic value system that requires the following components of education to be implemented and developed:

- Moral values - honesty, responsibility, love, discipline,

- Aesthetic values - recognizing, accepting and preserving the beauty, the human being, the environment,

- Intellectual values - love for knowledge, education, self-awareness,

- Legal values - the formation of the qualities of law and obligation, respect for oneself and others;

- Physical values - personal hygiene, health, daily routine, etc.

Thus, in the context of solving the issue of the formation and orientation of the primary schoolers' value system, we consider it appropriate to make the following conclusion: "To formulate and fix the value legacy in accordance with contemporary requirements, to display it everywhere, which is considered a priority of the general education", because the generation shaped by the national value system will have a dignified future.

\section{References}

Kogut A.A. (2012). On the issue of diagnosing the development of communicative activity of senior preschoolers. A man \& Education, 4 (33), pp. 161-164.

Topuzyan A. O. (2008). Education Concept/ Project/. "Pedagogy" Scientific-Methodological Analytical Journal 7-8, pp. 4-25.

Isaev I.F. (2004). Professional and pedagogical culture of a teacher (p. 208). M.: Academy.

Abakumova N.N., Malkoval.Yu. (2007). Competency-based approach in education: organization and diagnosis (p.368). Tomsk: Tomsk State University.

Schwartz Methodology (Schwartz Value Questionnaire (TS) / Schwartz Value Test). Source: $\quad$ https://psycabi.net/testy/322-test-tsennosti-shvartsa-tsennostnyioprosnik-tso-shvartsa-metodika-shvartsa 